\title{
Development of Nursing Informatics Competencies Evaluation Index System of Clinical Nurses
}

\author{
Yuan CHEN ${ }^{\mathrm{a}}$, Lijuan YAN ${ }^{\mathrm{a}}$, Weiliang ZHENG ${ }^{\mathrm{a}}$, Bixia LIN ${ }^{\mathrm{a}}$, \\ Linjing WU ${ }^{\mathrm{a}}$, Zhimin $\mathrm{WU}^{\mathrm{a}}$ and Polun $\mathrm{CHANG}^{\mathrm{b}}$ \\ ${ }^{a}$ Xiamen Cardiovascular Hospital, Xiamen University \\ ${ }^{\mathrm{b}}$ National Yang-Ming University
}

\begin{abstract}
For lack of effective and reliable assessment tools of nursing informatics competencies (NIC), we used literature research method, nominal group technology (NGT) and delphi technique to construct an evaluation index system of NIC for clinical nurses, which can provide reference for establishing a training system of talents of nursing informatics.
\end{abstract}

Keywords. Nursing informatics competency, evaluation indicator system, delphi technique

\section{Introduction}

Development plan of national nursing career (2016-2020 $)^{[1]}$ clearly points out that it is necessary to vigorously promote the construction of nursing information, so as to improve efficiency and quality of nursing services and reduce the workload of clinical nurses. NIC is a comprehensive ability of knowledge, skills and attitudes expressed through various activities of nursing informatics ${ }^{[2]}$. NIC can not only enhance the accuracy and completeness of nursing documentation, but also facilitate the promotion of quality of nursing services and reduce work errors ${ }^{[3]}$. However, most of the clinical nurses' are weak in NIC due to have not been received training courses of nursing informatics ${ }^{[4]}$. The construction of nursing informatization in China started late, and there are few related theoretical studies. In addition, there is no report on effective and reliable assessment tools of NIC ${ }^{[5]}$. Therefore, it is urgent for us to establish an evaluation index system of NIC of clinical nurses.

\section{Objective}

To develop an evaluation index system of NIC for clinical nurses. 


\section{Methods}

We selected the item pool through literature research method and Nominal Group Technique. Then, 12 experts involving nursing management, nursing education, clinical nursing and medical informatics were invited in two rounds of delphi to establish the evaluation indicators. Yaahp (a software) was used to determine the weight of each index through the analytic hierarchy process.

\section{Results}

Experts familiar coefficient, judgment coefficient and authority coefficient was 0.86 , 0.82 and 0.84 , respectively; In the second round, the index system included 3 first level indexes and 45 second level indexes; The variation coefficients of each item was $0.00 \sim 0.24$, and Kendall's W was 0.54. As we can see in the Table 1 below, "Computer comprehensive ability" ranked first in the first-level index, which indicated that "computer comprehensive ability" is the most basic and core ability that clinical nurses should be possessed.

Table 1. The score of indexes of NIC for clinical nurses.

\begin{tabular}{llll}
\hline Evaluation indexes & Score $(\overline{\mathrm{X}} \pm \mathrm{S})$ & $\mathbf{C V}$ & Weight value \\
\hline Computer comprehensive ability & $4.92 \pm 0.29$ & 0.06 & 0.5470 \\
Comprehensive application ability & $4.17 \pm 0.39$ & 0.09 & 0.1085 \\
Information ability & $4.83 \pm 0.39$ & 0.08 & 0.3442 \\
\hline
\end{tabular}

\section{Conclusion}

The entrenched assessment indicator system was scientific and reliable. We plan to build a training framework of NIC, which are applicable to three levels (general nurse, information nurse, information expert) of clinical nurses in China, so as to provide reference for the training and evaluation of talent of nursing informatics.

\section{References}

[1] National Health Commission of the People's Republic of China. 2016 Nov; http://www.ndrc.gov.cn/fzg ggz/fzgh/ghwb/gjigh/201707/t20170720_855027.html

[2] Staggers N, Gassert CA, Curran C. Informatics competencies for nurses at four levels of practice. J Nurs Educ. 2001 Oct;40(7):303-16.

[3] Canadian Nursing Informatics Association (CNIA). Assessing the informatics education needs of Canadian Nurses Educational Institution component educating tomorrow's nurses-Where's nursing informatics. 2014 Jan; http://www.cnia.ca/documents/OHIHfinal.pdf.

[4] Fan N, Yin YL, Guo XR ,et al. Research status and comparative analysis of nursing information ability in clinical nursing staff. Chinese Journal of Modern Nursing. 2016 Jun;22(18):2662-2664.

[5] Li BB, Wu XY. Reflection on nursing information construction in big data era. Journal of Nursing Scienc. 2016 Sep;31(4):91-92. 